\title{
Our management of anesthesia in elective and emergency cesarean surgery: A retrospective evaluation of the last ten years
}

\author{
Elektif ve acil sezaryen ameliyatlarında anestezi yönetimimiz: \\ Son on yılın retrospektif değerlendirilmesi
}

\author{
Özgür ÖZMEN ${ }^{1}$, Zakir ARSLAN², Mürsel EKINCi ${ }^{3}$, İbrahim TÖR ${ }^{4}$, Duygu KARA ${ }^{2}$, Muhammet Ahmet KARAKAYA
}

\section{ABSTRACT}

The choice of anesthesia used in cesarean operations is determined by the patient's clinical status, the experience of the anesthetist, the urgency of surgery and the patient's wishes. This study evaluated anesthetic practices in cesarean surgery performed in the preceding 10 years in our Maternity Hospital, Turkey. Hospital computer system records and file archives between 2006 and 2015 were screened. Anesthesia techniques used in elective and emergency cesarean surgery were recorded. The distribution of these techniques by years was then analyzed. A total of 28.986 cesarean sections (cases) were performed in our hospital in 2006-2015. Eighty-four percent of them were emergency and $16 \%$ of them were elective CSs. General anesthesia was used in $4848(17 \%)$ and regional anesthesia in 24.138 (83\%) patients, while combined spinal-epidural anesthesia was used in $2 \%$ and epidural anesthesia in 1\% of the patients. Regional anesthesia was used frequently in our clinic similar to European countries. Spinal anesthesia was the most commonly preferred method of regional anesthesia in our clinic. However, especially in emergency cases combined spinal-epidural or epidural anesthesia was not applied. We think that combined spinal-epidural anesthesia should be applied more frequently in elective cases.

Keywords: Regional anesthesia, obstetric anesthesia, retrospective study
Öz

Sezaryen ameliyatlarında kullanılan anestezi uygulaması seçimi; hastanın kliniği, anestezistin tecrübesi, cerrahinin aciliyeti ve hastanın isteğine göre belirlenir. Bu çalışmada, kadın doğum hastanemizde son 10 yılda yapılan sezaryen operasyonlarındaki anestezi uygulamaları değerlendirilmiştir. 2006-2015 yılları arasında hastanemiz bilgisayar sistem kayıtları ve dosya arşivleri tarandı. Elektif ve acil olarak yapılan sezaryen ameliyatlarında kullanılan anestezi yöntemleri kaydedildi. Bu yöntemlerin yıllara göre dağılımı analiz edildi. Hastanemizde 2006-2015 yılları arasında toplam 28986 sezaryen ameliyatı gerçekleștirilmiștir. Sezaryenlerin \%84'ü acil, \%16'sı elektifti. Dört bin sekiz yüz kırk sekiz (\%17) hastada genel anestezi, 24138 (\%83) hastada bölgesel anestezi tercih edilmis olup, hastaların \%2'sinde kombine spinal-epidural, \%1'inde ise epidural anestezi tercih edilmiştir. Kliniğimizde bölgesel anestezi yöntemlerinin kullanımı Avrupa ülkelerine benzer şekilde yüksek bulunmuştur. Kliniğimizde bölgesel anestezi yontemi olarak en Çok spinal anestezi tercih edilirken, özellikle acil vakalarda hiç kombine spinal-epidural ve epidural anestezi uygulanmadığı görülmektedir. Elektif vakalarda ise kombine spinal-epidural uygulamasının artırılması gerektiği düşüncesindeyiz.

Anahtar kelimeler: Bölgesel anestezi, obstetrik anestezi, retrospektif çalışma

\section{Giriş}

Anne ve bebek sağlığı için sezaryen ameliyatlarında tercih edilecek anestezi yöntemi çok önemlidir ${ }^{1,2}$. Bu ameliyatlarda uygulanacak anestezi yönetimi; cerrahinin aciliyeti, hastanın klinik durumu, anestezi uzmanının deneyimi ve hasta tercihine göre seçilme- lidir. Sezaryen operasyonlarında genel anestezi (GA) ve rejyonal (bölgesel) anestezi (RA) [kombine spinalepidural (KSEA), epidural anestezi (EA), spinal anestezi (SA)] yöntemleri uygulanmaktadır.

GA'nin hava yolu kontrolü sağlaması, acil durumlarda hızlı indüksiyon, daha az hipotansiyon ve daha iyi

Received: 27.07.2016

Accepted: 30.08 .2016

${ }^{1}$ Erzincan University School of Medicine, Mengücekgazi Regional Training and Research Hospital, Department of Anaesthesiology

${ }^{2}$ Erzurum Regional Training and Research Hospital, Department of Anaesthesiology

${ }^{3}$ Kars Harakani Public Hospital, Department of Anaesthesiology

${ }^{4}$ Erzurum Nene Hatun Maternity and Children Hospital, Department of Anaesthesiology

5istanbul Medipol University, School of Medicine, Department of Anaesthesiology

Yazışma adresi: Özgür Özmen, Erzincan University School of Medicine, Mengücekgazi Regional Training and Research Hospital, Department of Anaesthesiology, Erzincan

e-mail: dr.ozgurozmen@yahoo.com.tr 
kardiyovasküler stabilite oluşturması gibi avantajları vardır. Fetusta solunum depresyonu ve özellikle gebelerde daha sık karşılaşılan mide içeriği aspirasyonu ile entübasyon güçlüğü GA'nin ön plana çıkan dezavantajlarıdır ${ }^{3,4}$.

Postoperatif analjezi sağlaması, anestezik ajanların anne ve fetusu daha az etkilemesi, günlük yaşamsal aktivitelere dönüşün daha erken dönemde olması, anne ve bebek arasındaki iletişimin daha erken başlaması RA'nin avantajlarıdır,6. RA'ye bağlı oluşan hipotansiyonun fetal asidoz ve hipoksiye yol açabilmesi, dura perforasyonuna bağlı uzun süren baş ağrısı RA'nin en ciddi dezavantajlarıdır

GA komplikasyonlarının RA'ye göre 17 kat fazla olduğu bildirilmektedir ${ }^{8}$. Bu da birçok ülkede olduğu gibi ülkemizde de RA tekniklerini ön plana çıkarmaktadır ${ }^{9,10}$.

Kadın doğum uzmanları tarafında acil sezaryen endikasyonu belirtilen hastalarda da RA tekniklerinin (özellikle SA) ilk tercih olarak seçilmesi gerektiğini belirten çalışmalar mevcuttur ${ }^{11,12}$.

Retrospektif olarak yapılan bu çalışmada, kadın hastalıkları ve doğum hastanemizde 2006-2015 yılları arasında yapılan 28986 acil ve elektif sezaryen ameliyatında kullanılan anestezi tekniklerini incelemeyi amaçladık. Yıllar arasında kullanılan anestezi metotlarındaki farklılığı değerlendirdik.

\section{GEREÇ ve YÖNTEM}

Hastanemiz Etik Kurulunun 20.10.2015 tarih ve 2015/12-112 sayılı onayı alındı. Kadın hastalıkları ve doğum hastanesinde 2006-2015 yılları arasında acil ve elektif sezaryen ameliyatı yapılan hastalar retrospektif olarak değerlendirildi. Çalışmamızda, 28986 hastanın bilgisayar kayıtları ve arşiv dosyaları tarandı. Sezaryen operasyonlarında kullanılan anestezi tekniklerinin yıllara göre kullanımları belirlendi. Bu dağııım GA ile RA olarak ve RA ise KSEA, EA, SA alt sınıflarına ayrılarak kaydedildi. Acil ve elektif sezaryenler için bu gruplar ayrı ayrı oluşturuldu. Illk beş yıl ve son beş yıl verileri karşılaştırılarak uygulama oranlarına bakıldı. Çalışmamızda elde ettiğimiz verilerin istatistiksel analizi "Statistical Package for Social Sciences (SPSS) for Windows 15,0 (SPSS, Inc., Chicago, IL, USA)" programı kullanılarak yapıldı. Sayımla elde edilen verilerin karşılaşItırılması amacıyla ki-kare testi ve Fisher Exact testi kullanıldı. Veriler sayı ve yüzde (n, \%) olarak belirtildi. $p<0,05$ anlamlı kabul edildi.

\section{BULGULAR}

Kadın hastalıkları ve doğum hastanesinde 2006-2015 yılları arasında 24413'ü (\%84) acil, 4573'ü (\%16) elektif sezaryen olmak üzere toplam 28986 sezaryen ameliyatı gerçekleştirilmiştir. Hastaların tamamında tercih edilen anestezi yöntemini incelediğimizde 4848 (\%17) hastada GA, 24138 (\%83) hastada RA ter-

Tablo 1. Yıllara göre acil ve elektif sezaryenlerde uygulanan anestezi yöntemleri.

\begin{tabular}{|c|c|c|c|c|c|c|c|c|}
\hline \multirow[b]{2}{*}{ Yıl } & \multicolumn{4}{|c|}{ Acil Sezaryen } & \multicolumn{4}{|c|}{ Elektif sezaryen } \\
\hline & $\begin{array}{l}\text { GA } \\
\text { n (\%) }\end{array}$ & $\begin{array}{l}\text { SA } \\
\text { n (\%) }\end{array}$ & $\begin{array}{l}\text { KSEA } \\
\text { n (\%) }\end{array}$ & $\begin{array}{l}\text { EA } \\
\text { n (\%) }\end{array}$ & $\begin{array}{l}\text { GA } \\
\text { n (\%) }\end{array}$ & $\begin{array}{l}\text { SA } \\
\text { n (\%) }\end{array}$ & $\begin{array}{l}\text { KSEA } \\
\text { n (\%) }\end{array}$ & $\begin{array}{l}\text { EA } \\
\text { n (\%) }\end{array}$ \\
\hline 2006 & $588(33)$ & $1209(67)$ & $0(0)$ & $0(0)$ & $144(15)$ & $735(78)$ & $48(5)$ & $14(2)$ \\
\hline 2007 & $445(25)$ & $1379(75)$ & $0(0)$ & $0(0)$ & $197(24)$ & 549 (67) & 27 (3) & $41(6)$ \\
\hline 2008 & $209(12)$ & $1609(88)$ & $0(0)$ & $0(0)$ & $204(27)$ & $394(52)$ & $52(7)$ & $113(14)$ \\
\hline 2009 & $508(26)$ & $1469(74)$ & $0(0)$ & $0(0)$ & $48(9)$ & $67(12)$ & $268(49)$ & $165(30)$ \\
\hline 2010 & $481(20)$ & $1946(80)$ & $0(0)$ & $0(0)$ & $163(27)$ & $394(66)$ & $36(6)$ & $1(0,2)$ \\
\hline 2011 & $388(17)$ & $1991(83)$ & $0(0)$ & $0(0)$ & $50(16)$ & $228(73)$ & $23(7)$ & $11(4)$ \\
\hline 2012 & $422(14)$ & $2603(86)$ & $0(0)$ & $0(0)$ & $38(17)$ & $177(78)$ & $6(2,7)$ & $4(2,3)$ \\
\hline 2013 & $318(11)$ & 2745 (89) & $0(0)$ & $0(0)$ & $16(14)$ & $62(55)$ & $30(26)$ & $6(5)$ \\
\hline 2014 & $287(10)$ & $2633(90)$ & $0(0)$ & $0(0)$ & $25(15)$ & $101(60)$ & $28(17)$ & $13(8)$ \\
\hline 2015 & $312(10)$ & $2871(90)$ & $0(0)$ & $0(0)$ & $5(6)$ & $48(50)$ & $25(26)$ & $17(18)$ \\
\hline Toplam & $3958(16)$ & $20455(84)$ & $0(0)$ & $0(0)$ & 890 (19) & $2755(60)$ & $543(12)$ & $385(9)$ \\
\hline
\end{tabular}

Veriler n (\%) şeklinde gösterilmiştir. GA: Genel Anestezi, SA: Spinal Anestezi, KSEA: Kombine Spinoepidural Anestezi, EA: Epidural Anestezi 
cih edilmiş olup, hastaların \%2'sinde KSEA, \%1'inde ise EA tercih edilmiştir.

Acil operasyonlarda tüm yılların ortalaması alındığında \%16 oranında GA, \%84 oranında SA ile gerçekleştirilmiş olup, KSEA ve EA uygulamaları tercih edilmemiştir. Acil operasyonların yıllara göre dağılımına baktığımızda 2006 yılında \%33 oranında GA, \%67 oranında ise SA tercih edilmiş olup, yıllar içerisinde SA oranı artarak 2015 ve 2014 yıllarında \%90 civarına ulaşmıştır. Elektif operasyonlarda tüm yılların ortalamasına baktığımızda \%19 oranında GA, \%60 oranında SA, \%12 oranında KSEA, \%9 oranında ise EA uygulamaları tercih edilmiştir (Tablo 1).

2006-2010 ve 2011-2015 yılları arası acil vakalarda uygulanan anestezi yöntemleri Tablo 2'de verilmiş olup, aralarında istatistiksel olarak anlamlı fark olduğu tespit edilmiştir ( $p<0,01)$. 2006-2010 ve 20112015 yılları arası elektif vakalarda uygulanan anestezi yöntemleri Tablo 3'te verilmiş olup, aralarında istatistiksel olarak anlamlı fark olduğu tespit edilmiştir $(p<0,01)$.

Tablo 2. 2006-2010 ve 2011-2015 yılları arasında acil sezaryenlerde uygulanan anestezi yöntemleri.

\begin{tabular}{|c|c|c|c|c|}
\hline & & 2006-2010 & 2011-2015 & $p$ \\
\hline GA & n (\%) & $2231(23)$ & $1727(12)$ & \\
\hline SA & n (\%) & 7612 (77) & $12843(88)$ & \\
\hline KSEA & n (\%) & $0(0)$ & $0(0)$ & $<0,01$ \\
\hline EA & n (\%) & $0(0)$ & $0(0)$ & \\
\hline
\end{tabular}

Veriler $n$ (\%) şeklinde gösterilmiştir. GA: Genel Anestezi, SA: Spinal Anestezi, KSEA: Kombine Spinoepidural Anestezi, EA: Epidural Anestezi

Tablo 3. $2006-2010$ ve 2011-2015 yılları arasında elektif sezaryenlerde uygulanan anestezi yöntemleri.

\begin{tabular}{lllll}
\hline & & $\mathbf{2 0 0 6 - 2 0 1 0}$ & $\mathbf{2 0 1 1 - 2 0 1 5}$ & $\mathbf{p}$ \\
\hline GA & $\mathrm{n}(\%)$ & $756(20)$ & $134(15)$ & \\
SA & $\mathrm{n}(\%)$ & $2139(59)$ & $616(68)$ & \\
KSEA & $\mathrm{n}(\%)$ & $431(12)$ & $112(11)$ & $<0,01$ \\
EA & $\mathrm{n}(\%)$ & $334(9)$ & $51(6)$ & \\
\hline
\end{tabular}

Veriler $n$ (\%) şeklinde gösterilmiştir. GA: Genel Anestezi, SA: Spinal Anestezi, KSEA: Kombine Spinoepidural Anestezi, EA: Epidural Anestezi

\section{TARTIŞMA}

Ülkemizde yaygın olarak uygulanan girişimlerden olan sezaryen operasyonlarında GA ve RA yöntemleri uygulanmaktadır ${ }^{4}$. Çalışmamızda, acil ve elektif sezaryen operasyonu geçiren hastaların büyük çoğunluğunda RA kullanıldığı görülmüştür. GA komplikasyonlarının RA'ye göre daha fazla olması nedeniyle, birçok ülkede olduğu gibi ülkemizde de RA tekniklerini ön plana çıkarmaktadır ${ }^{9,10}$. Hastanemiz bünyesinde yapılan sezaryen operasyonlarında, RA seçiminin \%83 olduğu ve RA'nin hasta ve doktor açısından öncelikli anestezi uygulaması olarak tercih edildiği görülmüştür. Ülkemizde sezaryen operasyonlarında kullanılan anestezi tekniğiyle ilgili çalışmalarda bölgesel anestezi uygulamasının gittikçe arttığı tespit edilmiştir ${ }^{14}$. Ancak, acil ve elektif operasyonlarda karşılaştırmalı olarak nasıl bir anestezi yöntemi uygulandığına dair literatürde yeterince çalışma olmadığını gözlemlemekteyiz.

Acil sezaryen ameliyatlarında anestezi uzmanına aciliyet durumunun haberi verildikten sonraki süre 30 $\mathrm{dk}^{\prime} \mathrm{y}$ ' geçmemelidir ${ }^{15}$. Anne ile bebeğin yaşamı ciddi şekilde risk arz etmiyorsa bu süre hastanın anestezi öncesi hazırlanması ve spinal anestezi yapılması için gereken süreyi karşılamaktadır ${ }^{11}$. Kadın doğum uzmanları tarafından acil sezaryen endikasyonu belirtilen hastalarda da RA tekniklerinin (özellikle SA) ilk tercih olarak seçilmesi gerektiğini belirten çalışmalar mevcuttur ${ }^{11,12}$.

Kliniğimizde bölgesel anestezinin acil vakalarda kullanımının arttığı ve bu oranın 2014 ve 2015 yıllarında \%90 civarında olduğu görülmektedir. Almanya'da sezaryen operasyonlarında sıklıkla kullanılan anestezi metotunun $\% 90,8$ oranla SA olduğu bildirilmekte ve 2002 yılından sonra bölgesel anestezi yöntemlerinde artma olduğu görülmektedir ${ }^{9}$. Çalışmamızda da acil sezeryan vakalarında SA'nin diğer anestezi yöntemlerine göre ön plana çıktığı görülmektedir. Sezaryenlerde bölgesel yöntemleri İngiltere'de \%90, Amerika Birleşik Devletleri'nde \%72, Norveç'te \%95, İsveç'te \%90 düzeylerinde kullanılmaktadır ${ }^{16,17}$. Sezaryen operasyonlarında kliniğimizde de dünya genelinde uygulanan en yaygın anestezi tekniği olan bölgesel 
anestezi uygulaması neredeyse aynı oranlarda tercih edilmektedir.

Dünyada sezaryen anestezisi için epidural anestezi, spino-epidural anestezi, spinal anestezi gibi bölgesel anestezi teknikleri uygulansa da en sık kullanılan yöntem olan spinal anestezidir. Sezaryen operasyonlarında bölgesel anestezi kullanım oranları İspanya'da \%98 olup, bölgesel yöntemlerden de SA'nin \%75 oranında kullanıldığı bildirilmiştir ${ }^{18}$. Kliniğimizde acil sezaryen operasyonları için uygulanan bölgesel anestezi tekniklerinin tamamı spinal anestezi şeklindedir. SA yönteminin acil sezaryen operasyonlarının tamamında tercih edilmesinin nedenlerini: Anestezi hekimi açısından SA'nin diğer tekniklerden daha kolay gerçekleştirilmesi, hızlı uygulanabilinmesi ve başarı yüzdesinin daha fazla bir metod olması, kadın doğum hekimi açısından ise cerrahiye daha hızlı başlayabilmesi ve yeter kadar kas gevşekliği sağlayabilmesi olarak söyleyebiliriz ${ }^{19,20}$. Kliniğimizde spinal anestezi uygulamasının \%90 civarında olmasını, hastalarımız açısından bölgesel anestezi yöntemin tatmin edici bir şekilde tüm yöntemlerin avantajlarının ve dezavantajların anlatılıp bölgesel anestezinin daha avantajlı olduğuna ikna olmalarına bağlayabiliriz.

Elektif sezaryen operasyonlarında ortalama \%81 oranında bölgesel anestezi kullanılmış olup, 2015 yılında ise \%94 oranında RA tercih edilmiştir. Elektif operasyonlarda son yıllarda her ne kadar yüksek oranlarda RA tercih edilmiş olsa da ortalamaya baktığımızda KSEA \%12 ve EA \%9 oranında uygulanmıştır. Bunun nedeni olarak, işlem süresinde ve anestezi süresindeki uzamanın olduğu düşüncesindeyiz. KSEA'nin EA'den daha fazla uygulanmasının nedeni olarak nispeten işlem süresi uzun olsa da, spinal anesteziye benzer şekilde anestezinin hızı başlaması ve uzamış vakalarda devamlı anestezi uygulanabilmesi açısından önemli avantaj sağlamasıdır. Bununla birlikte, postoperatif analjezi yöntemi olarak güvenli ve uzun süre uygulanabilmesi klinisyenlerce KSEA'nin son yıllarda daha fazla tercih edilmesini sağlamıştır ${ }^{21}$. Bu avantajları göz önünde bulundurulduğunda KSEA'nin elektif sezaryen vakalarının yeterli uygulama süresine imkan vermesi nedeniyle daha fazla tercih edilme- si gerektiği düşüncesindeyiz.

Uygun anestezi yönteminin seçiminde anestezi uzmanı ve cerrahın iletişimi önemli ve gerekli bir durum olarak karşımıza çıkar. Ülkemizde yapılan bir anket calışmasında, kadın hastalıkları ve doğum doktorları tanıdıkları hastalarına bölgesel anestezi yöntemleri$\mathrm{ni}$, diğer hastalarına ise genel anestezi yönteminin kullanılmasını istedikleri, anestezi uzmanlarının ise tüm hastalarında büyük oranlarda bölgesel anestezi tekniklerini kullandıklarını söylemişlerdir ${ }^{4}$. Elektif sezaryenlerde spinal anestezi tercihinin genel anesteziye göre, ameliyathanenin kullanılış süresinde ilave bir uzamaya neden olmadığı ve fetus için herhangi bir farklılık oluşturmadığı yapılan bir çalışmada gösterilmiştir ${ }^{22}$. Başka bir çalışmada ise, anne ve fetus açısından bölgesel anestezi yöntemlerinin diğer yöntemlere göre daha güvenilir olduğu söylenmektedir ${ }^{13}$.

Kliniğimizde bölgesel anestezi yöntemlerinin kullanımı Avrupa ülkelerine benzer şekilde yüksek bulunmuştur. Klinik olarak bölgesel anestezi tekniklerinden en çok SA'yi tercih ederken, özellikle acil vakalarda hiç KSEA ve EA uygulanmadığı görülmektedir. Elektif vakalarda ise KSEA uygulamasının artırılması gerektiği düşüncesindeyiz.

\section{KAYNAKLAR}

1. Göktuğ A, Özayar E, Oba Ş, ve ark. Sezaryen Olgularında Uygulanan Rejyonel Anestezi Tekniklerinin Yan Etkilerinin Sonuçları. Türk Anest Rean Der Dergisi 2007;35:145-51.

2. Dahl V, Spreng UJ. Anaesthesia for urgent (grade 1) caesarean section. Curr Opin Anaesthesiol 2009;22:352-6. http://dx.doi.org/10.1097/ACO.0b013e3283294c37

3. McDonnell NJ, Paech MJ, Clavisi OM et al. Difficult and failed intubation in obstetric anaesthesia: an observational study of airway management and complications associated with general anaesthesia for caesarean section. Int J Obstet Anesth 2008;17:292-7. http://dx.doi.org/10.1016/j.ijoa.2008.01.017

4. Kocamanoğlu IS, Sarıhasan B, Sener B et al. Methods and complications of Anesthesia in cesarean/section operations: Retrospective evaluations of 3552 cases. Turkiye Klinikleri J Med Sci 2005;25:810-16.

5. McCool WF, Packman J, Zwerling A. Obstetric anesthesia: changes and choices. J Midwifery Women's Health 2004;49:505-13.

http://dx.doi.org/10.1016/j.jmwh.2004.08.028

6. Gürsoy C, Ok G, Aydın D, et al. Effect of Anaesthesia Methods for Regaining Dailly life Activities in Cesarean Patients. Turk J Anaesth Reanim 2014;42:71-9. 
http://dx.doi.org/10.5152/TJAR.2014.96630

7. Gogarten W. Spinal anaesthesia for obstetrics. Best Pract Res Clin Anaesthesiol 2003;17(3):377-92. http://dx.doi.org/10.1016/S1521-6896(02)00116-7

8. Lynch J, Scholz S. Anaesthetic-related complications of caesarean section. Zentralb/ Gynakol 2005;127(2):91-5. http://dx.doi.org/10.1055/s-2005-836335

9. Marcus HE, Behrend A, Schier R, et al. Anesthesiological management of Caesarean sections: nationwide survey in Germany. Anaesthesist 2011;60:916-28. http://dx.doi.org/10.1007/s00101-011-1931-y

10. Gulhaş N, Şanlı M, Ozgul U, ve ark. Sezaryenlerde Anestezi Yonetimi: Retrospektif Değerlendirme. Inonu Universitesi Tıp Fakultesi Dergisi 2012;19:142-5. http://dx.doi.org/10.7247/jiumf.19.3.3

11. Levy DA. Anaesthesia for Cesarean section. Contin Educ Anaesth Crit Care Pain 2001;1:171-6. http://dx.doi.org/10.1093/bjacepd/1.6.171

12. Diemunsch P, Pottecher J, Chassard D. Anesthetic management in case of previous cesarean section. J Gynecol Obstet Biol Reprod 2012;41(8):817-21. http://dx.doi.org/10.1016/j.jgyn.2012.09.035

13. Toker K, Yılmaz AS, Gürkan Y, et al. Anesthesia for Caesarean surgery, 5-year retrospective evaluation. TARCM 2003;31:2630.

14. Aksoy M, Aksoy AN, Dostbil A, et al. Anaesthesia Techniques For Caesarean Operations: Retrospective Analysis Of Last Decade. Turk J Anaesthesiol Reanim 2014;42(3):128-132. http://dx.doi.org/10.5152/TJAR.2014.80774

15. Association of Anaesthetists of Great Britain and Ireland and
Obstetric Anaesthesists' Association. Guidelines for obstetric anaesthesia services; 2005.

16. Palmer SK. Anaesthesia care for obstetric patients in the United States. $1^{\text {st }}$ edition. London: Springer-Verlag, Regional Analgesia in Obstetrics 2000: 3-10. http://dx.doi.org/10.1007/978-1-4471-0435-3_1

17. Kangas-Saarela T, Bang U. Regional Anaesthesia in Scandinavia. $1^{\text {st }}$ edition. London: Springer-Verlag, Regional Analgesia in Obstetrics 2000: 27-33.

http://dx.doi.org/10.1007/978-1-4471-0435-3_4

18. Sabate S, Gomar C, Canet J, et al. Obstetric anesthesia in Catalonia, Spain. Med Clin (Barc) 2006;126:40-5.

19. Farragher R, Datta $S$. Recent advances in obstetric anesthesia. J Anesth 2003;17:30-41. http://dx.doi.org/10.1007/s005400300005

20. McCool WF, Packman J, Zwerling A. Obstetric anesthesia: changes and choices. J Midwifery Women's Health 2004;49:505-13. http://dx.doi.org/10.1016/j.jmwh.2004.08.028

21. Blanshard HJ, Cook TM. Use of combined spinal-epidural by obstetric anaesthetists. Anaesthesia 2004;59:922-3. http://dx.doi.org/10.1111/j.1365-2044.2004.03918.x

22. Sungur MO, Havas $F$, Karadeniz $M$, ve ark. Elektif sezaryen ameliyatlarında anestezi seçiminin ameliyat odası kullanım süresine etkisi: spinal mi genel mi? Turk Anest Rean Der Dergisi 2012;40:136-43.

http://dx.doi.org/10.5222/JTAICS.2012.136 